\title{
A Study on Viewpoint of Teachers on Normal and Mentally Retarded Students
}

\author{
Sodabeh Mirsadeghi \\ University Putra Malaysia, Serdang, Malaysia
}

\begin{abstract}
In this paper, the author has an investigation on viewpoint of teachers on normal and mentally retarded students. It is to be noted that the present research is of descriptive. The population of the present research included normal and mentally retarded teachers of elementary schools of Tehran Province. Two classes of normal and mentally retarded teachers as classes of research population were considered. Sample was taken and 300 teachers of normal students and 210 teachers of mentally retarded students were selected as statistical sample. Attitude Metric Inventory of Margaret De Clark was used to determine positive and negative viewpoints, EQ (Emotional Quotient) and attribution style of normal and mentally retarded students which was accepted with a validity of 0.89 . T-statistical method of the two independent groups and research findings were analyzed.
\end{abstract}

Keywords: viewpoint, EQ (Emotional Quotient), document style

\section{Introduction}

Teachers are responsible for a vital role in education. Teachers' satisfactions with their education and their interest rate have wonderful effects on the academic achievement of students. Increase in communication between teachers and students' learning disabilities has created a variety of perspectives, including that of teachers and students' communication barriers and obstacles pointing out environmental communication. Communication between teachers and students' learning disabilities, includes the most sensitive measures of education, because teachers cannot easily communicate with their learning disabled children.

Student's personality, such as document styles and emotional intelligence, and identification of these features reflect the views of teachers on students. Characteristics of students are with a favorable ground for increased communication between teachers and students

\section{Aim and Scope}

This article reviews the normal students and teachers, teachers' attitudes towards students with learning disabilities to attribution styles, and emotional intelligence dealing with practical information for improving the educational outcomes achieved learning disabled children.

This study aims to examine the differences between the attitudes of teachers in both normal students and teachers of exceptional students to consider regular and disabled students' learning styles and emotional intelligence documents. Human resource development has to try to identify problems and also provide suitable patterns to learning disabled students.

Sodabeh Mirsadeghi, Ph.D., Faculty of Psychological Science, University Putra Malaysia. 
The assumption is that teachers' attitudes between normal students and teachers of exceptional students to regular and disabled students' learning document styles and emotional intelligence are different.

\section{Importance and Necessity of Research}

Learning disabled students have a special defect learning systems and cannot use public education properly. This leads to a new trend in the general and special education to change the system through their learning disabled students in the shortest time to maximize their flourishing.

Thus, with emphasis on factors affecting the students' learning outcomes and the use of modern educational technology, new curriculum must provide to learning disabled students.

The most important factor in learning disabled students is teacher. Students with learning disabilities have difficulty communicating with teachers, and in most cases, bring to the isolation and social relations which are impaired.

Therefore, it is necessary to determine teachers' attitudes towards learning disabled students and emotional intelligence in order to increase academic motivation. This research could cover a small part of these studies.

\section{Study Scheme}

The study was on female primary school teachers in regular and special education students in Tehran in 2009-2010. Three hundred teachers in ordinary schools and 210 teachers from special schools had formal training in areas where exceptional children were selected as sample.

Attitude Questionnaire of Margaret De Clark was used to determine a positive attitude, negative attitude, style, emotional intelligence, and learning disabilities. The author used normal students and teachers of exceptional student as the statically population. Students in this study were divided into two groups (normal and learning disabled) at four levels (high capacity-high effort, high capacity-low effort, low ability-high effort, and low ability-low effort).

In order to analyze the data and answer research questions, $T$-model of two independent groups (in order to compare the attitudes of regular and special teachers) was applied.

Most of the normal school teachers' teaching experience was 17 to 19 years and for the exceptional schools, teachers' teaching experience was 14 to 16 years, and the majority of regular teachers' education level was BA (Bachelor of Art) but for special schools, teachers' education level was under BA.

\section{Result and Conclusions}

The author brings Figures 1 and 2 as sample here.

$T$-values were obtained with the emphasis on the rate, which can pose that there is a significant difference between mean normal and exceptional teachers in the variables of a positive attitude, negative attitude and attitude towards learning disabled students with high ability attribution style of top efforts. Thus, with reference to the means of both groups, normal student's teachers showed a higher average at variables of negative attitudes and attribution style to learning disabled students with high potential-high efforts.

While teachers of learning disabled students with exceptional ability in the variable of positive attitude towards the top ability-top effort, showed a higher average.

The author finds the answers to these main questions as follow:

(1) Is there any difference between normal students and teachers of exceptional student to regular and 
disabled students' learning styles documentation?

(2) Is there any difference between normal students and teachers of exceptional student to regular and disabled students’ learning emotional intelligence?

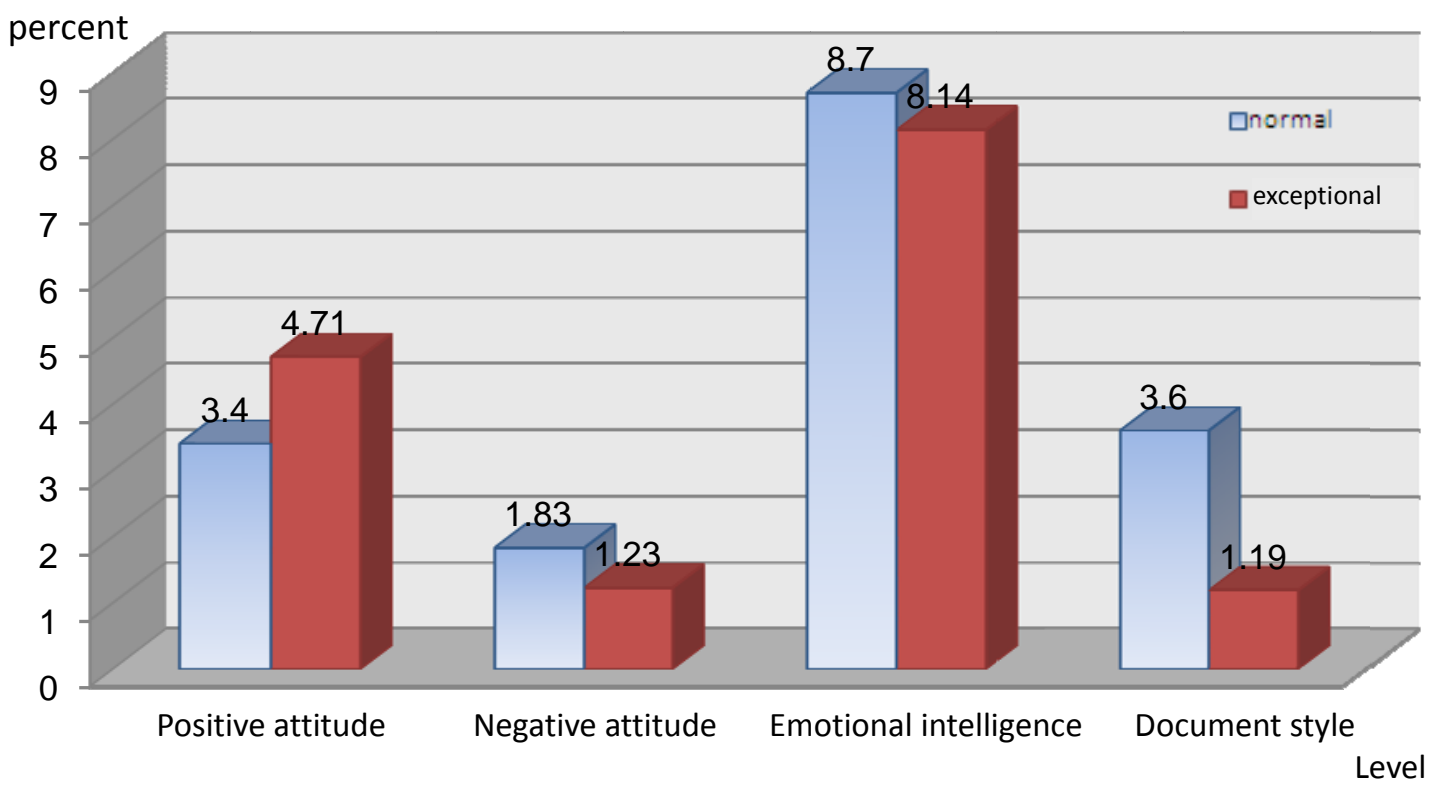

Figure 1. "Teacher attitude" towards the lower ability students with high abilities-top effort.

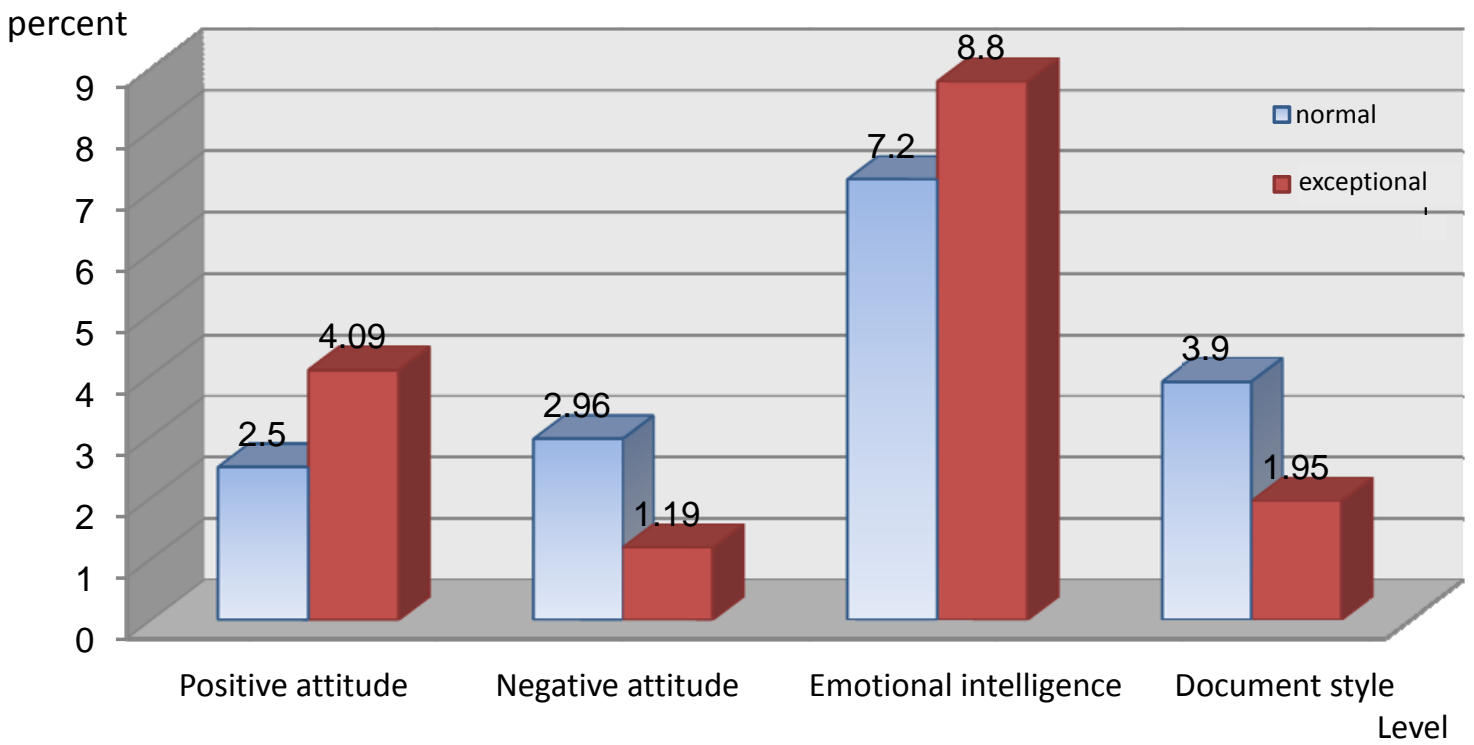

Figure 2. "Teacher attitude” towards normal students with high abilities-top effort.

Paying attention to the results, regular teachers have negative attitudes to learning disabled students with high potential-high effort, but exceptional teachers have positive attitudes towards these students.

Finally, ordinary teachers more than exceptional teachers believe that the failure rate is high in the future to learning disabled students with high potential-high effort. 
In each of eight groups of students, exceptional teachers are higher than normal. Finally, the teachers' attitude towards the style of documents, it was found that higher than normal teachers, special educators believe that the failure rate of these students is more in the future.

The results showed that there are significant differences between the mean attitude of ordinary teachers and special teachers to the emotional intelligence of students (in six groups of normal students with low ability-high effort, low ability-low effort and high ability students with learning disabilities have high effort, high ability-low effort, low ability-high effort, and low ability-low effort). In each of six groups of students, the average teacher is exceptionally higher than normal teachers, so exceptional teachers of ordinary teachers believe that students in these six groups are of higher emotional intelligence.

\section{References}

Anderson. (2001). Symbolic psychologic: A model of attiludinal cognition. Behavioral Science, 3, 1-13.

Arkin, R. M., Gleason, J. M., \& Johnston, S. (1976). Effects of perceived choice, expected outcome, and observed outcome of an action on the causal attribution of actors. Journal of Experimental and Social Psychology, 12, 151-158.

Bechara. (2000). A relational obligations approach to the foot-in-the-mouth effect. Journal of Applied Social Psychology, 24, 546-556

Barown, J. (2000). An introduction to motivation (vol. 31). New York, von Nostrand.

Baker, H. (2003). Introduction to mental health in the exceptional children. New York: The Macmillan Company.

Bar-On, R. (2000). The emotional quotient inventory (EQ-i): Technical manual. Toronto, Canada: Multi-Health Systems, Inc.. 